\title{
Transient Hyperinsulinemic Hypoglycemia Linked to PAX6 Mutation
}

\author{
Jee-Min Kim, Seul-Ki Kim, Shin-Hee Kim, Won-Kyoung Cho $\mathbb{1}$, Kyoung-Soon Cho, Min-Ho Jung, \\ Byung-Kyu Suh (1) and Moon-Bae Ahn * (1)
}

Citation: Kim, J.-M.; Kim, S.-K.; Kim

S.-H.; Cho, W.-K.; Cho, K.-S.; Jung,

M.-H.; Suh, B.-K.; Ahn, M.-B.

Transient Hyperinsulinemic

Hypoglycemia Linked to PAX6

Mutation. Medicina 2021, 57, 582.

https://doi.org/10.3390/

medicina57060582

Academic Editor: Nikolaos Papanas

Received: 11 April 2021

Accepted: 3 June 2021

Published: 7 June 2021

Publisher's Note: MDPI stays neutral with regard to jurisdictional claims in published maps and institutional affiliations.

Copyright: (c) 2021 by the authors. Licensee MDPI, Basel, Switzerland. This article is an open access article distributed under the terms and conditions of the Creative Commons Attribution (CC BY) license (https:/ / creativecommons.org/licenses/by/ $4.0 /)$.
Department of Pediatrics, College of Medicine, Catholic University of Korea, Seoul 06591, Korea; jeejennykim@gmail.com (J.-M.K.); seulki12633@gmail.com (S.-K.K.); tigger1018@naver.com (S.-H.K.); wendy626@catholic.ac.kr (W.-K.C.); soon926@catholic.ac.kr (K.-S.C.); jmhpe@catholic.ac.kr (M.-H.J.); suhbk@catholic.ac.kr (B.-K.S.)

* Correspondence: mbahn@catholic.ac.kr; Tel.: +82-2-2258-6756 or +82-2-537-4544

\begin{abstract}
Prolonged hyperinsulinemic hypoglycemia in infancy can result in developmental sequelae. A mutation in the paired box-6 gene (PAX6) has been reported to cause disorders in oculogenesis and neurogenesis. A limited number of cases of diabetes mellitus in adults with a PAX6 mutation suggest that the gene also plays a role in glucose homeostasis. The present case report describes a boy with a PAX6 mutation, born with anophthalmia, who underwent hypoglycemic seizures starting at 5 months old, and showed a prediabetic condition at 60 months. This patient provides novel evidence that connects PAX6 to glucose homeostasis and highlights that life-threatening hypoglycemia or early onset glucose intolerance may be encountered. The role of PAX6 in glucose metabolism and insulin regulation should be further investigated.
\end{abstract}

Keywords: paired box-6 gene; aniridia; congenital hyperinsulinism; glucose intolerance; diabetes mellitus

\section{Introduction}

Hyperinsulinemic hypoglycemia $(\mathrm{HH})$ is the most common cause of recurrent hypoglycemia during the neonatal and infantile periods, and excessive glucose utilization due to either exogenous or endogenous hyperinsulinism may lead to severe neurological sequelae. Primary $\mathrm{HH}$ is triggered by mutations in genes related to the development of the pancreas resulting in the inappropriate secretion of insulin, and approximately 15 genes, including ABCC8, KCNJ11, GLUD1, GCK, HADH, and SLC16A1, have been identified [1]. Secondary $\mathrm{HH}$ can occur from a variety of syndromes, including intrauterine growth retardation, maternal diabetes mellitus (DM), birth asphyxia, and postoperative complications of gastrointestinal surgery [2]. In patients diagnosed with $\mathrm{HH}$, it is important to develop an early intervention to prevent permanent neurological damage from prolonged hypoglycemia.

The role of the paired box-6 gene $(P A X 6)$ and its encoding proteins has provided insight into various transformative discoveries by their biological and molecular action as master regulatory proteins and their involvement with oculogenesis, pancreatogenesis, and neurogenesis [3]. With PAX6 mutations, a number of cases associated with aniridia have been documented, while only a few cases associated with impaired glucose tolerance or DM, which are potential consequences of PAX6 action on the biosynthesis and secretion of insulin, have been reported [4,5]. In animal models, PAX6 is known to play an essential role in the differentiation and function of $\beta$-cells [6].

Proper PAX6 expression is important for maintaining $\beta$-cell identity and glucose homeostasis; therefore, PAX6 should be one of the candidate genes to evaluate when impaired glucose tolerance or DM is presented in congenital form. Hyperglycemia induced by low insulin secretory capacity is a theoretical rationale; on the other hand, insulin hypersecretion seems challenging to explain. While studies examining the relationship 
between $\mathrm{HH}$ and PAX6 are rarely reported, we describe, for the first time, a child with multiple hypoglycemic episodes due to hyperinsulinemia possibly triggered by a novel PAX6 mutation.

\section{Case Description}

A male infant was born at $40+5$ weeks of gestation, and was the only child born to Korean parents with no family history of consanguinity or past medical history. The patient's birth weight was $3.3 \mathrm{~kg}$ (25th-50th percentile) and head circumference was $34 \mathrm{~cm}$ (25th-50th percentile). He was delivered by normal vaginal delivery during spontaneous labor. He was born in good condition with normal Apgar scores and no antenatal concerns, except for bilateral anophthalmia noticed by fetal ultrasound. Both eyeballs were missing; therefore, the patient was referred to an ophthalmologist soon after birth to discuss ocular prosthesis and was subsequently discharged home. No dysmorphic features including skin pigmentations, umbilical hernia, or hepatomegaly were observed. A physical examination revealed a normal prepubertal male genitalia with Tanner stage 1 . Abdominal sonography detected no hepatomegaly or other structural abnormality in the kidney or pancreas. He did not have remarkable syndromic features other than anophthalmos and multiple hypoglycemic seizure episodes.

The patient was 5-months old when he first visited the emergency room (ER) due to an afebrile generalized tonic-clonic seizure lasting $2 \mathrm{~min}$ at home. The seizure ceased upon ER arrival, and the patient was mentally alert, showing good activity with no specific findings upon physical examination. Serum was immediately collected, and the serum glucose was $25 \mathrm{mg} / \mathrm{dL}$, with increased insulin and c-peptide in the absence of metabolic acidosis, which was suggestive of $\mathrm{HH}$. Serum $\beta$-hydroxybutyrate, free fatty acids, lactate, ammonia, cortisol, and thyrotropin levels were normal (Table 1). No urine ketone was present.

Table 1. Critical samples at two hypoglycemic seizure attacks at the age of 5 and 39 months, and fasting sample at the age of 60 months.

\begin{tabular}{|c|c|c|c|}
\hline \multirow{2}{*}{ Parameters (Units) (Reference Range) } & \multicolumn{3}{|c|}{ Age } \\
\hline & 5 Months & 39 Months & 60 Months \\
\hline Glucose (mg/dL) (50.0-100.0) & 25.0 & 38.0 & 156.0 \\
\hline $\begin{array}{c}\text { Insulin }(\mu \mathrm{U} / \mathrm{mL}) \\
\text { (hypoglycemic: }<2.5 \text {; fasting: } 1.0-30.0)\end{array}$ & 14.1 & 17.3 & 3.1 \\
\hline C-peptide $(\mathrm{ng} / \mathrm{mL})(1.1-3.3)$ & 2.4 & 2.1 & 0.7 \\
\hline$\beta \mathrm{OHB}(\mu \mathrm{mol} / \mathrm{L})(28.0-128.0)$ & 24.1 & 27.2 & 30.8 \\
\hline $\mathrm{HbA} 1 \mathrm{c}(\%)(4.4-6.0)$ & 4.0 & 4.6 & 6.1 \\
\hline FFA $(\mu \mathrm{Eq} / \mathrm{L})(130.0-770.0)$ & 193.0 & 181.6 & 161.0 \\
\hline Ammonia $(\mu \mathrm{g} / \mathrm{dL})(20.0-80.0)$ & 72.0 & 80.6 & 51.0 \\
\hline Cortisol $(\mu \mathrm{g} / \mathrm{dL})(9.4-26.1)$ & 8.6 & 12.1 & 8.8 \\
\hline $\mathrm{pH}(7.3-7.4)$ & 7.4 & 7.4 & 7.3 \\
\hline $\mathrm{HCO}_{3}{ }^{-}(\mathrm{mmol} / \mathrm{L})(23.0-30.0)$ & 25.4 & 18.4 & 25.3 \\
\hline
\end{tabular}

$\beta \mathrm{OHB}$, beta-hydroxybutyrate; FFA, free fatty acids; $\mathrm{HCO}^{-}$, bicarbonate; $\mathrm{HbA1c}$, glycosylated hemoglobin.

$2 \mathrm{~mL} / \mathrm{kg}$ of $10 \%$ dextrose fluid was intravenously administered and the blood glucose level shortly normalized to $109 \mathrm{mg} / \mathrm{mL}$, which was considered to be euglycemic. No family history of hypoglycemia, DM, or other conditions associated with glucose intolerance were documented. The elevation of serum glucose and insulin levels was observed $(45 \mathrm{mg} / \mathrm{dL}$ and $13.1 \mu \mathrm{U} / \mathrm{mL}$, respectively) after post-glucagon stimulation (0.03 $\mathrm{mg} / \mathrm{kg}$ ). Brain magnetic resonance imaging (MRI) identified no abnormal signal intensities or structural anomalies, except for nearly absent bilateral orbital globes with atrophic optic nerves, while pancreas MRI detected no structural defect (Figure 1). Sanger sequencing of $A B C C 8, K C N J 11, G C K$, and BMP4 identified no pathogenic variants. Soon after starting oral diazoxide ( $5 \mathrm{mg} / \mathrm{kg} /$ day divided into 3 doses), a blood glucose level within the normoglycemic range ( $80-120 \mathrm{mg} / \mathrm{dL}$ ) was achieved. The parents were advised to regularly 
monitor blood glucose level, promptly react to the patient's irritability from long-term fasting, and feed him frequently. The parents refused to apply continuous glucose monitoring sensors, and thus mandatory and routine monitoring of pre- and postprandial glucose was recommended. The patient was discharged, without experiencing additional hypoglycemic episodes.

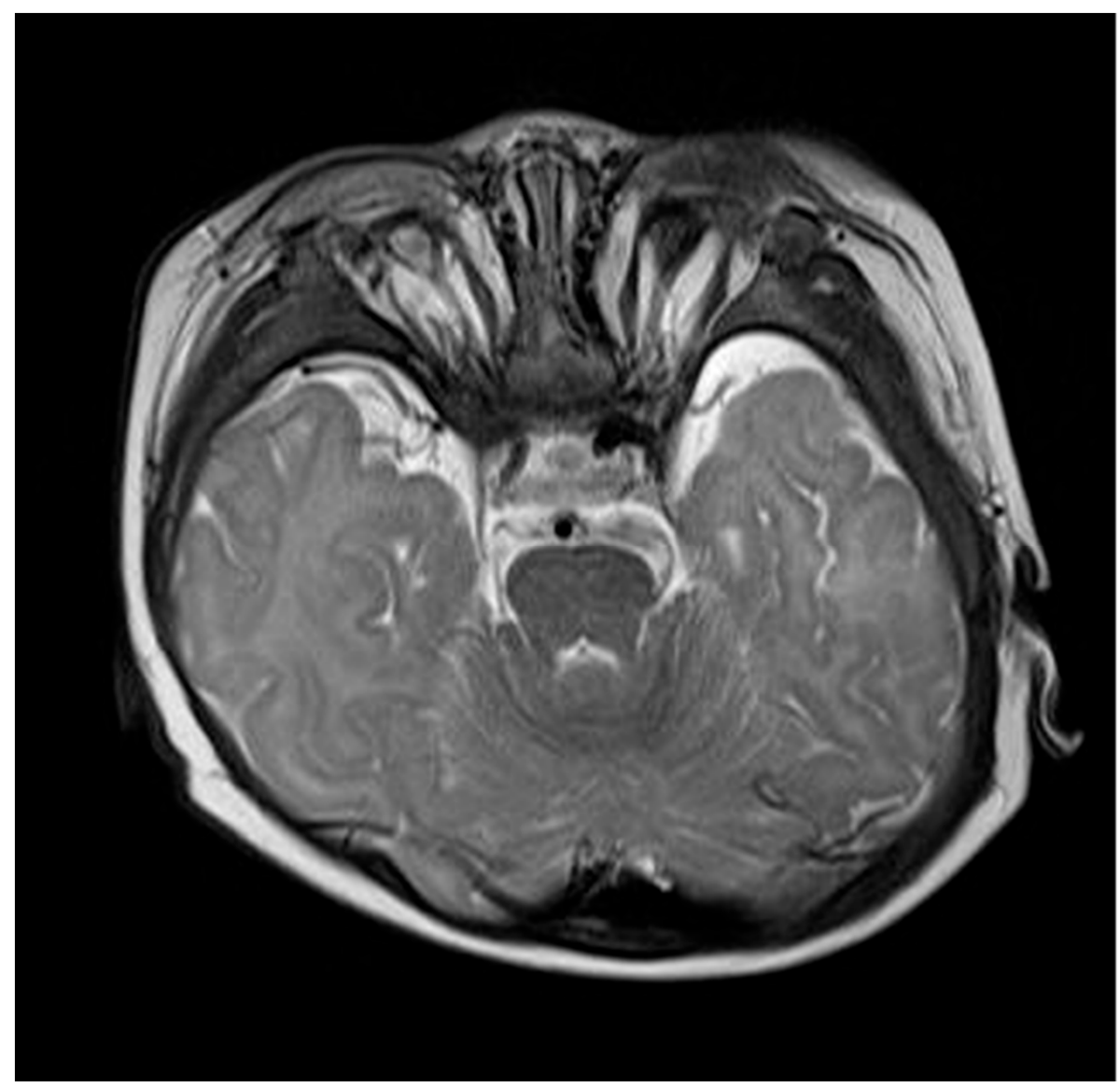

Figure 1. Brain magnetic resonance imaging at 6 months old demonstrated bilateral anophthalmia.

During follow-ups in the outpatient clinic, the patient showed normal growth and reached the neurodevelopmental milestone of his age (he was able to read Braille). Neither hypo- nor hyper-glycemia associated symptoms were observed while self-monitoring of blood glucose checks maintained within a stable range (70-100 mg/dL for pre-prandial and 150-180 mg/dL for postprandial). Follow-up insulin, c-peptide, and glycated hemoglobin (HbA1c) levels (5.5-8.5 $\mu \mathrm{U} / \mathrm{mL}, 0.7-1.1 \mathrm{ng} / \mathrm{mL}$ and $4.6-5.5 \%$, respectively) remained within the euglycemic range. $5 \mathrm{mg} / \mathrm{kg} /$ day of diazoxide was sufficient for the patient to stay euglycemic, without the need for escalating the dose or adding octreotide. Until 36 months of age, he did not show signs of any adverse effects to diazoxide. We decided to slowly taper out the dosage of diazoxide to see whether the condition was temporary since there was no genetic evidence associated with permanent hyperinsulinemic hypoglycemia while the patient remained euglycemic. A weekly reduction of $1 \mathrm{mg} / \mathrm{kg}$ took place and diazoxide administration was completely stopped at 38 months of age.

The patient revisited the ER for the 2nd hypoglycemic attack after 4 weeks of diazoxide discontinuation. Serum glucose of the critical sample was $38 \mathrm{mg} / \mathrm{mL}$, and other biochemical results again demonstrated potential $\mathrm{HH}$ (Table 1). Emergent glucose infusion and re-administration of $5 \mathrm{mg} / \mathrm{kg} /$ day diazoxide resulted in recovery from hypoglycemia. Without recurrence of additional hypoglycemic episodes, the patient was discharged and continued on minimum dose diazoxide. Targeted next generation sequencing (NGS) of 
20 genes associated with congenital diabetes (ABCC8, BLK, CEL, EIF2AK3, FOXP3, GATA4, GATA6, GCK, HNF1A, HNF4A, HNF1B, INS, KCNJ11, KLF11, NEUROD1, PAX4, PAX6, PDX1, PTF1A, and ZFP5) was performed, and a heterozygous variant of 188th nucleotide change from cytosine to guanine, resulting in a change of the 63rd amino acid sequence, serine to cysteine at exon 6 of PAX6 (NM_00280.4) was identified; this was confirmed by Sanger sequencing. According to the ACMG guideline, the alternation was classified as pathogenic since it was located in a mutational hot spot or well-studied functional domain without benign variation, absent/rare in population databases, and novel missense change at an amino acid residue where a different missense change determined to be pathogenic had been seen before $[7,8]$.

Diazoxide therapy was reinitiated at 39 months and was continued for 2 years; further hypoglycemic events were not observed. We discussed a reduction in diazoxide dosage with the parents; however, they were afraid to do so due to previous seizure episodes. At the age of 60 months, the patient had intermittent hyperglycemia (>200 mg/dL), and laboratory findings on fasting state indicated a prediabetic condition (Table 1). Anti-pancreatic antibodies against glutamic acid decarboxylase, islet antigen 2, zinc transporter, and islet cell were not detected. Intermittent hyperglycemia and borderline $\mathrm{HbA} 1 \mathrm{c}$ level $(6.1 \%)$ presenting at the minimum dose of diazoxide led to concern of possible DM, although the mechanism is yet to be explained in mutations presenting as hyperinsulinemic hypoglycemia progressing to DM. Thus, diazoxide was reduced every other day. The patient remained asymptomatic and showed euglycemic trends during dose tapering. After cessation of diazoxide, the 6- and 12-month fasting glucose and $\mathrm{HbA1c}$ levels were 86 and 5.6\% and 89 and $5.5 \%$, respectively.

\section{Discussion}

PAX6 spans $23 \mathrm{~kb}$ on $11 \mathrm{p} 13$ and includes 14 exons and 422 amino acids [8]. Since its discovery in 1991, PAX6 studies have spanned many decades and have unveiled the biological roles and molecular mechanisms of associated proteins. In a wide spectrum of impaired ocular morphogenesis, aniridia is a casual consequence of heterozygous lossof-function mutations in PAX6 [9]. Approximately $80 \%$ of congenital aniridia are due to PAX6 mutations, and more than 300 mutations have been identified to date $[10,11]$. The role of PAX6 in glucose metabolism has recently been studied; hypoglycemia or DM may be triggered in patients with PAX6 mutations, by aberrant glucagon and insulin signaling pathways of pancreatic $\alpha$ - and $\beta$-cells [1,12]. Among published PAX6-induced congenital aniridia cases, this is the first report demonstrating a transitional pattern from hypoglycemia to hyperglycemia in early childhood.

Congenital $\mathrm{HH}$ is a genetic disorder characterized by either diffuse or focal abnormalities of the islets of Langerhans, with an incidence ranging from 1/50,000 to 1/2500 live births [13]. Less than 20 candidate genes associated with congenital $\mathrm{HH}$ have been identified [2]. Even though studies have been conducted to reveal the role of $P A X 6$, its direct mechanism regulating glucose homeostasis is still unknown. Nevertheless, evidence from both animal and human studies has suggested that genetic alteration of PAX6 affects islet function, which in turn regulates glucose metabolism [3,14]. According to Hart et al., glucagon production was significantly reduced in response to inactivation of PAX6 expression [15]. Ablation of $P A X 6$ in mouse pancreatic endocrine cells resulted in a reduction of cells secreting insulin and glucagon [15]. Mice with heterozygous PAX6 mutation had a prohormone convertase 1/3 deficiency, resulting in abnormal proinsulin processing [16]. Hypoglycemia is a possible consequence of glucagon deficiency; however, the pathophysiological mechanism of postnatal hyperinsulinemia in our patient is poorly understood. According to Zheng et al., hyperinsulinemia induces PAX6 expression in endometrial epithelial cells, indicating that $P A X 6$ under insulin-resistant conditions may act as a potent transcriptional regulator and deregulate pathogenic mechanisms in patients with polycystic ovarian syndrome [16]. Since the HH episode was repeated but not persistent and no genetic mutation regarding congenital $\mathrm{HH}$ was identified, increased insulin secretion could 
have been caused by PAX6 mutation-induced islet cell dysfunction, which subsequently led to $\mathrm{HH}$ during early childhood.

While the majority of published cases regarding PAX6 mutations have focused on the clinical consequences of oculo- and neurogenesis, reports on its endocrinologic associations are scarce. Transitions to early onset DM have rarely been reported, and impaired glucose intolerance is mildly presented [17]. Motoda et al. reported a 63-year-old man with aniridia and insulin-dependent DM whose $\mathrm{HbA1c}$ was $9.7 \%$ and c-peptide was undetectable (c,483_486dupTTGG) [18]. Nishi et al. reported a similar case in a 27-year-old female (c.402del2) [17]. Both adult patients showed low insulin secretory capacity and ended up requiring lifelong insulin therapy. Our patient experienced a prediabetic condition (impaired glucose intolerance) at 60 months of age, and his age was the youngest ever reported. Hyperglycemia is a possible consequence of long-term diazoxide therapy, however the risk of developing early onset diabetes cannot be excluded even after the discontinuation of diazoxide therapy. Shimo et al. reported a 40-yearold woman with hypogonadotropic hypogonadism and borderline growth hormone deficiency and raised the possibility that a heterozygous PAX6 mutation could induce partial hypopituitarism [19]. Screening for anterior pituitary hormones in our patient was normal for the same sex and age group. Although our patient showed normal insulin secretory capacity, close laboratory observation is critical to detect potential early onset DM.

Diazoxide, the first line treatment of congenital $\mathrm{HH}$, binds to the linker region of the SUR1 subunit of the KATP channels and suppresses $\beta$-cell insulin secretion by forcing the channels to remain open [20]. Early diazoxide administration was a solid judgment for our patient during $\mathrm{HH}$ events, even prior to genetic diagnosis. However, excessive diazoxide therapy may increase the risk of DM or hyperglycemia; thus, its use in patients who are prone to glucose intolerance requires consideration [21]. Recent studies have proposed diazoxide as the first drug of choice for $\mathrm{HH}$ with a starting dosage of $5 \mathrm{mg} / \mathrm{kg} /$ day, which could be increased up to $20 \mathrm{mg} / \mathrm{kg} /$ day [2,22]. Due to the possible adverse effects of diazoxide, such as fluid retention, hypertrichosis, and cardiac failure, optimal dosage should be the minimal dosage as long as euglycemia is achieved [22]. In addition, the effect of diazoxide on glucagon-producing alpha cells is unknown. Intermittent hyperglycemia was a fortunate warning for our patient to discontinue diazoxide and reduce the risk of DM. In PAX6-mutated patients, any treatment that could affect glycemic control requires special attention, and blood glucose should be carefully monitored.

Additional information would have helped to clarify the role of PAX6 in our patient. Serum glucagon levels were not measured due to the unavailability of the assay; hence, the documentation of hypoglucagonemia was not feasible, and glucagon compensation against hypoglycemia could not be evaluated. An 18-F-Dopa PET scan would have been useful to further detect the hyperinsulinemic cause. While the targeted NGS panel offered a clear conclusion, further genetic testing, such as whole exome or genome sequencing, may provide additional insights into our patient's condition.

\section{Conclusions}

In conclusion, this case report details a PAX6-mutated anophthlamic boy manifesting with transient hypo- and hyperglycemia. PAX6 mutations may lead to either lifethreatening hypoglycemia or early onset glucose intolerance and diabetes. Further investigation is warranted to clarify the role of PAX6 in aberrant glucose metabolism and islet cell hormone production.

Author Contributions: Conceptualization, J.-M.K.; methodology, M.-B.A.; software, J.-M.K.; validation, S.-K.K., S.-H.K., and W.-K.C.; formal analysis, K.-S.C.; investigation, M.-H.J.; resources, M.-H.J.; data curation, J.-M.K.; writing-original draft preparation, J.-M.K.; writing-review and editing, B.-K.S.; visualization, J.-M.K.; supervision, M.-B.A.; project administration, M.-B.A. All authors have read and agreed to the published version of the manuscript.

Funding: This research received no external funding. 
Institutional Review Board Statement: The study was conducted according to the guidelines of the Declaration of Helsinki, and approved by the Institutional Review Board of the Catholic University of Korea (KC21ZISI0149).

Informed Consent Statement: Informed consent was obtained from all subjects involved in the study.

Data Availability Statement: No new data were created or analyzed in this study. Data sharing is not applicable to this article.

Conflicts of Interest: The authors declare no conflict of interest.

\section{References}

1. Gosmain, Y.; Cheyssac, C.; Masson, M.H.; Guerardel, A.; Poisson, C.; Philippe, J. Pax6 Is a Key Component of Regulated Glucagon Secretion. Endocrinology 2012, 153, 4204-4215. [CrossRef]

2. Guemes, M.; Rahman, S.A.; Kapoor, R.R.; Flanagan, S.; Houghton, J.A.L.; Misra, S.; Oliver, N.; Dattani, M.T.; Shah, P.T. Hyperinsulinemic hypoglycemia in children and adolescents: Recent advances in understanding of pathophysiology and management. Rev. Endocr. Metab. Dis. 2020, 21, 577-597. [CrossRef] [PubMed]

3. Cvekl, A.; Callaerts, P. PAX6: 25th anniversary and more to learn. Exp. Eye Res. 2017, 156, 10-21. [CrossRef]

4. Mirrahimi, M.; Sabbaghi, H.; Ahmadieh, H.; Jahanmard, M.; Hassanpour, K.; Suri, F. A novel PAX6 Mutation Causes Congenital Aniridia with or without Retinal Detachment. Ophthalmic Genet. 2019, 40, 146-149. [CrossRef] [PubMed]

5. Yasuda, T.; Kajimoto, Y.; Fujitani, Y.; Watada, H.; Yamamoto, S.; Watarai, T.; Umayahara, Y.; Matsuhisa, M.; Gorogawa, S.; Kuwayama, Y.; et al. PAX6 mutation as a genetic factor common to aniridia and glucose intolerance. Diabetes 2002, 51, 224-230. [CrossRef]

6. Gosmain, Y.; Katz, L.S.; Masson, M.H.; Cheyssac, C.; Poisson, C.; Philippe, J. Pax6 is crucial for $\beta$-cell function, insulin biosynthesis, and glucose-induced insulin secretion. Mol. Endocrinol. 2012, 26, 696-709. [CrossRef] [PubMed]

7. Richards, S.; Aziz, N.; Bale, S.; Bick, D.; Das, S.; Gastier-Foster, J.; Grody, W.W.; Hegde, M.; Lyon, E.; Spector, E.; et al. Standards and guidelines for the interpretation of sequence variants: A joint consensus recommendation of the American College of Medical Genetics and Genomics and the Association for Molecular Pathology. Genet. Med. 2015, 17, 405-424. [CrossRef] [PubMed]

8. Qiu, J.-J.; Zhang, Q.; Geng, Z.-x.; Liu, M.; Zhong, Z.-1.; Chen, J.-j.; Liu, F. Identification of a novel PAX6 mutation in a Chinese family with aniridia. BMC Ophthalmol. 2019, 19, 10. [CrossRef]

9. Grant, M.K.; Bobilev, A.M.; Branch, A.; Lauderdale, J.D. Structural and functional consequences of PAX6 mutations in the brain: Implications for aniridia. Brain Res. 2021, 1756, 147283. [CrossRef] [PubMed]

10. Tzoulaki, I.; White, I.M.S.; Hanson, I.M. PAX6 mutations: Genotype-phenotype correlations. BMC Genet. 2005, 6, 27. [CrossRef]

11. Grønskov, K.; Olsen, J.H.; Sand, A.; Pedersen, W.; Carlsen, N.; Jylling, A.; Lyngbye, T.; Brøndum-Nielsen, K.; Rosenberg, T. Population-based risk estimates of Wilms tumor in sporadic aniridia. Human Genet. 2014, 109, 11-18. [CrossRef]

12. Tian, W.; Zhu, X.R.; Qiao, C.Y.; Ma, Y.N.; Yang, F.Y.; Zhou, Z.; Feng, J.P.; Sun, R.; Xie, R.R.; Lu, J.; et al. Heterozygous PAX6 mutations may lead to hyper-proinsulinemia and glucose intolerance: A case-control study in families with congenital aniridia. Diabet. Med. 2020, 38, e14456. [CrossRef] [PubMed]

13. Vlachopapadopoulou, E.A.; Dikaiakou, E.; Fotiadou, A.; Sifianou, P.; Tatsi, E.B.; Sertedaki, A.; Kanaka-Gantenbein, C.; Michalacos, $\mathrm{S}$. Detection of hepatocyte nuclear factor $4 \mathrm{~A}(\mathrm{HNF} 4 \mathrm{~A})$ gene variant as the cause for congenital hyperinsulinism leads to revision of the diagnosis of the mother. J. Pediatr. Endocrinol. Metab. 2020. [CrossRef]

14. Ahlqvist, E.; Turrini, F.; Lang, S.T.; Taneera, J.; Zhou, Y.; Almgren, P.; Hansson, O.; Isomaa, B.; Tuomi, T.; Eriksson, K.; et al. A common variant upstream of the PAX6 gene influences islet function in man. Diabetologia 2012, 55, 94-104. [CrossRef]

15. Hart, A.W.; Mella, S.; Mendrychowski, J.; van Heyningen, V.; Kleinjan, D.A. The developmental regulator Pax6 is essential for maintenance of islet cell function in the adult mouse pancreas. PLoS ONE 2013, 8, e54173. [CrossRef]

16. Zheng, X.R.; Pan, X.; Zhang, J.; Cao, X. Hyperinsulinemia-induced PAX6 expression promotes endometrial epithelial cell proliferation via negatively modulating p27 signaling. Biomed. Pharmacother. 2018, 97, 802-808. [CrossRef] [PubMed]

17. Nishi, M.; Sasahara, M.; Shono, T.; Saika, S.; Yamamoto, Y.; Ohkawa, K.; Furuta, H.; Nakao, T.; Sasaki, H.; Nanjo, K. A case of novel de novo paired box gene 6 (PAX6) mutation with early-onset diabetes mellitus and aniridia. Diabet. Med. 2005, 22, 641-644. [CrossRef] [PubMed]

18. Motoda, S.; Fujita, S.; Kozawa, J.; Kimura, T.; Fukui, K.; Ikuno, Y.; Imagawa, A.; Iwahashi, H.; Shimomura, I. Case of a novel PAX6 mutation with aniridia and insulin-dependent diabetes mellitus. J. Diabetes Investig. 2019, 10, 552-553. [CrossRef]

19. Shimo, N.; Yasuda, T.; Kitamura, T.; Matsushita, K.; Osawa, S.; Yamamoto, Y.; Kozawa, J.; Otsuki, M.; Funahashi, T.; Imagawa, A.; et al. Aniridia with a Heterozygous PAX6 Mutation in which the Pituitary Function was Partially Impaired. Intern. Med. 2014, 53, 39-42. [CrossRef]

20. Brar, P.C.; Heksch, R.; Cossen, K.; De Leon, D.D.; Kamboj, M.K.; Marks, S.D.; Marshall, B.A.; Miller, R.; Page, L.; Stanley, T.; et al. Management and Appropriate Use of Diazoxide in Infants and Children with Hyperinsulinism. J. Clin. Endocrinol. Metab. 2020, 105. [CrossRef] 
21. Kizu, R.; Nishimura, K.; Sato, R.; Kosaki, K.; Tanaka, T.; Tanigawara, Y.; Hasegawa, T. Population Pharmacokinetics of Diazoxide in Children with Hyperinsulinemic Hypoglycemia. Horm. Res. Paediatr. 2017, 88, 316-323. [CrossRef] [PubMed]

22. Demirbilek, H.; Hussain, K. Congenital Hyperinsulinism: Diagnosis and Treatment Update. J. Clin. Res. Pediatr. Endocrinol. 2017, 9, 69-87. [CrossRef] [PubMed] 